\title{
BRAIN RESEARCH
}

\section{Withdrawal from morphine or amphetamine: different effects on dopamine in the ventral-medial striatum studied with microdialysis}

\author{
Donita Crippens, Terry E. Robinson *

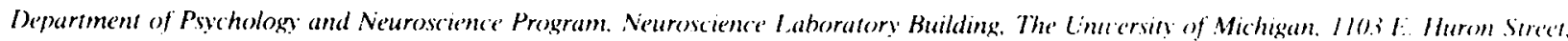 \\ Ann Arbor, MI 48104-1687. ISSA
}

Accepted 15 March 199.4

\begin{abstract}
The effect of withdrawal from chronic morphine or amphetamine treatment on dopamine (DA) neurotransmission in the ventral-medial striatum was studied by use of in vivo microdialysis. There was no effect of $24 \mathrm{~h}$ of amphetamine withdrawal on the basal concentration of DA in the ventral-medial striatum. Spontaneous morphine withdrawal $(24 \mathrm{~h})$ was associated with it significant decrease in the basal concentration of DA in dialysate. but following morphine replacement and naloxone-precipitated withdrawal variations in withdrawal symptoms were not related to variations in the concentration of DA in dialysate. It is suggested that: (1) the correlation between the extracellular concentration of DA in the ventral-medial striatum and the symptoms of morphine withdrawal may not be indicative of a necessary, causal relationship; and (2) a decrease in the extracellular concentration of DA in the ventral-medial striatum is not a common feature of drug withdrawal syndromes.
\end{abstract}

Key' words: Nucleus accumbens: Striatum; Drug dependence; Drug addiction

\section{Introduction}

The withdrawal or abstinence syndrome associated with the discontinuation of chronic opiate drug use is quite different to that associated with the discontinuation of chronic psychomotor stimulant drug use. For example, the former includes a variety of overt neurologic and vegetative signs, as well as subjective symptoms of distress, whereas the latter is more subtle, consisting primarily of subjective symptoms [7]. However, some of the subjective symptoms associated with opiate and psychomotor stimulant withdrawal are similar, including anxiety, depression, dysphoria and drug craving. The similarity of the subjective symptoms of withdrawal across drug classes has led some investigators to suggest they may have a common neurobiological substrate $[2,16,18]$.

Mesotelencephalic dopamine (DA) systems are known to play an important role in mediating the positive reinforcing effects of a variety of drugs of

\footnotetext{
* Corresponding author. Fax: (1) (313) 936-2690). E-mail: (jB92 (n um.cc umich edu.
}

abuse [21], and it has been suggested that an increase in DA neurotransmission is responsible for the subjective pleasurable aspects of drug action (see [14] for review and an alternative hypothesis). (Given this view. it is reasonable to hypothesize that a decrease in DA neurotransmission may be responsible for some of the unpleasant subjective symptoms associated with drug withdrawal syndromes $[2,16,18]$. Consistent with this idea, a decrease in the extracellular concentration of DA in the ventral striatum, as estimated by microdialysis, is reported to accompany the withdrawal syndromes associated with the abrupt discontinuation of chronic treatment with ethanol $[5,16,17]$, morphine $[1,2,13,16]$, amphetamine [16] or cocaine $[6,10,16,20]$. Some researchers, on the other hand. have reported that amphetamine withdrawal is not accompanied by a decrease in the extracellular concentration of DA in the ventral striatum $[4.19,22]$. The purpose of the two experiments reported here, therefore. was to reevaluate the relationship between changes in extracellular DA in the ventral-medial striatum, as estimated by in vivo microdialysis sampling, and the withdrawal syndromes associated with morphine vs. amphetamine abstinence. 


\section{Methods}

\subsection{Experiment 1: Withdrawal from morphine}

\section{Subjects}

Thirty male Sprague-Dawley rats, initially weighing $250-300 \mathrm{~g}$, were housed individually in stainless steel hanging cages. The animals had frec access to food and water and were maintained on a 14:10 h light/dark cycle.

\section{Surgen}

Each rat was ancsthetized with sodium pentobarbital, and standard stereotaxic techniques were used to place a 21 gauge thin-wall stainless steel guide cannula on the surface of the dura, above the ventral-medial striatum (nucleus accumbens; [12]). This was fixed in place with jeweler's screws and cranioplastic cement. The rats were allowed to recover from surgery for at least 4 days before beginning drug treatments.

\section{Drug pretreatment and dialysis procedures}

The animals were given daily injections of morphine sulfate (Mallinckrodt) or $0.9 \%$ saline for 15 days according to a regimen adapted from Acquas et al. [1]. The animals were injected subcutaneously twice per day (approximately $12 \mathrm{~h}$ apart) and the dose of morphine was escalated as follows: day $1,10 \mathrm{mg} / \mathrm{kg}$ (weight of the salt); day $2,20 \mathrm{mg} / \mathrm{kg}$; day $3-4,40 \mathrm{mg} / \mathrm{kg}$; day $5-6,60 \mathrm{mg} / \mathrm{kg}$; day $7-8,80 \mathrm{mg} / \mathrm{kg}$; day $9-10,100 \mathrm{mg} / \mathrm{kg} ;$ day $11-12,120 \mathrm{mg} / \mathrm{kg}$; day $13-15,140 \mathrm{mg} / \mathrm{kg}$.

On day 15 the animals were transferred from their home cages to the dialysis test chambers. Approximately $1 \mathrm{~h}$ later they received one additional injection, and $2 \mathrm{~h}$ later each rat was briefly restrained manually while a dialysis probe (see below) was lowered into the ventral-medial striatum via the previously implanted guide cannula. The probes were perfused with a sterile salt solution containing 145

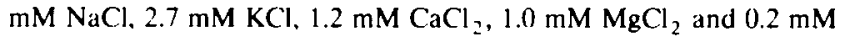
ascorbic acid, pH 7.3 [8], at a flow rate of $1.5 \mu \mathrm{l} / \mathrm{min}$ during probe implantation. The perfusion rate was then decreased to $0.3 \mu \mathrm{l} / \mathrm{min}$. and the animals were left undisturbed overnight in the test chamber.

Approximately $22 \mathrm{~h}$ after the last injection of morphine or saline, the flow rate through the probes was increased to $1.5 \mu \mathrm{l} / \mathrm{min}$. After a minimum stabilization period of $1 \mathrm{~h}$, at least three 30 -min samples of dialysate were collected. After this, all of the morphine-pretreated (dependent) rats were given an injection of $60 \mathrm{mg} / \mathrm{kg}$ of morphine (s.c.). half of the saline-pretreated rats received $10 \mathrm{mg} / \mathrm{kg}$ of morphine (s.c.), and the remaining saline-pretreated rats received $0.9 \%$ saline (s.c.). A dose of $60 \mathrm{mg} / \mathrm{kg}$ of morphine was used in morphinedependent rats because in pilot studies we determined this was sufficient to alleviate withdrawal symptoms for over $2 \mathrm{~h}$. Following the injection of morphine or saline three more $30-\mathrm{min}$ samples of dialysate were collected. Next, all of the saline-pretreated rats were given an injection of $1 \mathrm{mg} / \mathrm{kg}$ of naloxone (i.p.), half of the morphine-dependent rats received $1 \mathrm{mg} / \mathrm{kg}$ of naloxone (i.p.), and the remaining morphine-dependent rats received no injection. Following this, four additional 30-min samples of dialysate were collected. Thus, there were four experimental groups: (1) morphine-dependent rats given morphine only; (2) morphine-dependent rats given morphine followed by naloxone; (3) saline-pretreated rats given morphine followed by naloxone; and (4) saline-pretreated rats given saline followed by naloxone.

\section{Dialysis probes}

Concentric dialysis probes similar to those described by Robinson and Camp [15] were constructed from regenerated cellulose hollow dialysis fiber. One $\mathrm{mm}$ of stainless steel cannula and $7 \mathrm{~mm}$ of dialysis fiber extended below the skull surface. The dorsal $4 \mathrm{~mm}$ of fiber was coated with cyanoacrylate, leaving $3 \mathrm{~mm}$ of effective membrane in the ventral-medial striatum. All probes were tested for recovery of $D A$ in vitro prior to use, and there were no group differences in recovery. The average recovery value for DA was $21.27 \pm 0.43 \%$. Dopamine in dialysate was separated by HPLC and analyzed using electrochemical detection, as described previously [15].

\section{Behactior}

Behavior was monitored continuously throughout the 5 -h dialysis test session, and symptoms of withdrawal were scored using scales similar to those described by Blasig et al. [3]. Each incident of the following behaviors was scored as one point: teeth chattering, wet-dog shaking, jumping, and abdominal stretching. One continuous episode of teeth-chattering was scored as one point and duration was not recorded. In addition, the presence or absence of the following symptoms was recorded every $15 \mathrm{~min}$, and one point was scored if the symptom was present: diarrhea, ptosis, lacrimation and vocalization upon a light touch to the back. The total 'withdrawal score' for each animal was summed across 30 -min intervals, corresponding to the 30-min dialysis sample intervals. Thus, a high score on this scale

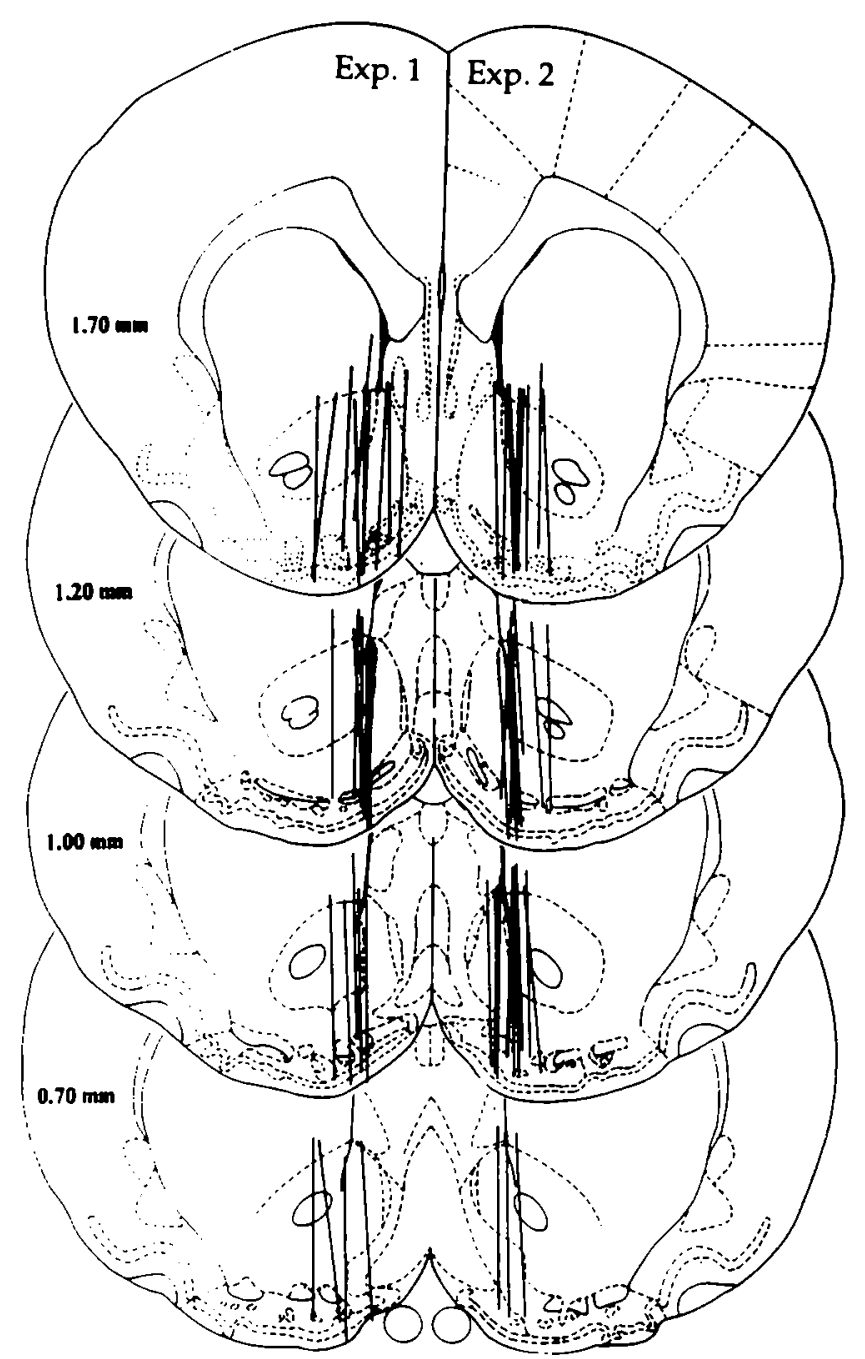

Fig. 1. Schematic drawings of coronal sections of the rat brain adapted from the atlas of Paxinos and Watson [12]. The locations of the dialysis surface of probes used in Expt. 1 (morphine withdrawal) are illustrated on the left half of the sections, and the right half of the sections shows the location of probes used in Expt. 2 (amphetamine withdrawal). 
reflects the frequent occurtence of the hehavions and symptoms aampled.

\section{Histologs}

Following the dialysis test session. cach animal was given al lethal dose of sodium pentobarbital. and then perfused through the heart with 10.19; saline and a lo\%; formalin solution. The brain was removed. frozen and sectioned. The sections were stained with (resyl violet and examined to determine the exact probe placement. Only those animals with probes that had at least 75'; of the dialysis surface within the ventral-medial striatum (primarily nucleus accumbens) were used in the experiment. The neurochemical data from four animals were excluded due to incorrect probe placentents or broken prohes, hut the behavioral data from these animals uere used.

\section{2. Fiperiment 2: Withdrawal from amphetaminc}

\section{Subjects and stargen}

Forty-three male Sprague-Dawley rats, initially weighing 250300 g. Here housed. and prepared with a guide cannula. as described in Ixpi. I.

\section{Drug trearment and dialy'sis procedures}

The rats were pretreated with two injections per day. 9-12 h apart, of 1$)$-amphetamine sulfate $(1.5 \mathrm{mg} / \mathrm{kg}$. i.p., weight of the salt) or 0.9\% saline for 14 consecutive days, as described by Rosselli et at. [16]. On day 15, the animals received only one injection of amphetamine or saline in the morning. Approximately $2 \mathrm{~h}$ later. half of the amphetamine-pretreated and half of the saline-pretreated animals were given chloral hydrate (i.p. $400 \mathrm{mg} / \mathrm{kg}$ ) in three separate injections $10 \mathrm{~min}$ apart [16]. While these animals were anesthetized. a dialysis probe (see above) was lowered into the ventral-medial striatum via the previously implanted guide cannula. and the rats were then placed into the dialysis test chambers. The remaining rats were only briefly restrained (manually) while the probe was lowered. During the implantation procedure the probes were perfused with the same salt solution as described in Expt. I. at a thow rate of 1.5 $\mu \mathrm{l} / \mathrm{min}$. Following probe implantation the pump was turned off and the animals were lett undisturbed in the est chambers overnight. Approximately $23 \mathrm{~h}$ after the last injection of amphetamine or saline.

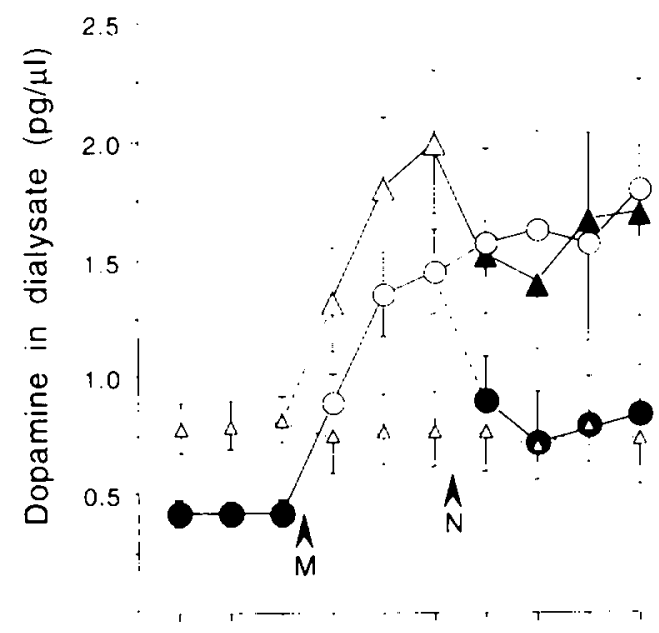

$\begin{array}{llllllllll}\mathrm{B} 1 & \mathrm{~B} 2 & \mathrm{~B} 3 & \mathrm{M} 1 & \mathrm{M} 2 & \mathrm{M} 3 & \mathrm{~N} 1 & \mathrm{~N} 2 & \mathrm{~N} 3 & \mathrm{~N} 4\end{array}$

30-Minute Intervals

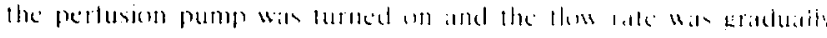

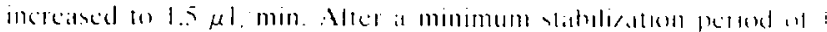

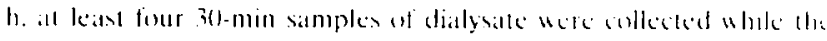
inimale were oblem isc undieculbed

The dialysis probes were an dencribed athene arth the Medage in

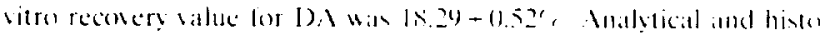
legical proceduren were as deveribed for lixpl.

Fig. 2. The mean (-S.F.M.) concentration of dopamine (IDA) in 30 -min dialysate samples obtained from the tentral-medial striatum. plotted as a function of time. Values were corrected for prothe recovery determined in vitu (set Suction 2). Intervals BI 13.2 reprosent basal values. intervals $\mathrm{Ml}-\mathrm{M} 3$ represent samples collected following morphine (or saline) administration, and intenals NI N.t represent samples collected following naloxone (or saline) adminis. tration. Triangles represent samples obtained from salline-pretreated rats and circles represent samples obtained from morphine-pre (reated (dependent) rats. All saline-pretreated rats $(n=1.3)$ and all morphine-dependent rats $(n-13)$ were pooled fo calculate the meial basal values (intervals $B 1-B 3$ ). Following the collection of three basal samples, the saline-pretreated group wats divided into lan subgroups. The larger triangles represent those rats that recisced 11 $\mathrm{mg} / \mathrm{kg}$ morphine $(n \cdot 8)$ and the smaller triangles represent those rats that received saline $(n=5)$. Morphine (or salline) wats given il the time indicated by the arrowhead labelled $M$. After morphine a saline administration. three additional 3(1)-min samples of dialysalc were collected (intervals MI M3). After this, both subgroups al saline-pretreated rats received $1.0 \mathrm{mg} / \mathrm{kg}$ naloxome, at the lim indicated by the arrowhead labelled $N$. and four additional samples of dialysate were collected. The black triangles represent, therefore. saline-pretreated rats that received morphine followed by naloxonc Following the collection of hasal samples, all of the morphinc-de pendent rats received fol $\mathrm{mg} / \mathrm{kg}$ of morphine and thres .30-min samples were collected (open circles, intenals Ml--M3). The mon phine-dependent group was then divided into tho subgroups. The closed circles (intervals $N$ I $N$ t) represent morphine-dependent rale that received $1.0 \mathrm{mg} / \mathrm{kg}$ naloxone $\left(n \cdot{ }^{\prime}\right)$, and the open circles (intervals $\mathrm{Nl}$-N4) represent morphine-dependent rats that received no further treatments (n 5). Summar of satisical analyses. 111 The mean hasal concentration of 1 ) $A$ wats significantly lower 11 morphine-dependent rats than in saline-pretcalted rats: comparison of the average of intervals $B \mid-B 3$ for each group. 1124$) 3.34$. $l$ P. $0.0(124$. (2) Morphine administration increased DS in buth saline-pretreated $(F(.3 .21)=3.5 .1 . P<0 .(0(0) 1)$ and morphine-depend

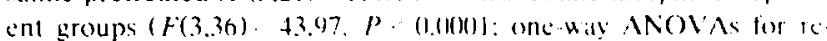
peated measures, intervals $B .3-M 3$ ) (3) Saline administration hatd no effect in saline-pretreated amimals, and there was no change in (). concentrations throughout the test session in this group ( $F(9.27)$ 11.74, $P=0.67)$. (4) In morphine-dependent animats naloxome sigmili. cantly decreased I)A concentrations for the remainder af the tent session (one-way ANOVA with repeated meisures, $f(+2 s)$ i. $P$ P.0001. and follow-up Fisher's PLSD test comparing interail M.3 vs. $\mathrm{N} 1-\mathrm{N} 4$ ). (5) In saline-pretreated animals given momphine naloxene decreased DA. hut this was not statistically significant hased on a repeated measures $A$ VOVA across intervals $M 3-\mathrm{N}-$ $(F(4,24)=1.74, P=0.173)$ : although there was a significant diffes. ence between interat $\mathrm{M} .3$ and the aterage of $\mathrm{V} \mid-\mathrm{N} 2$ hased on a

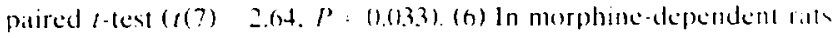
given maloxone. I) concentrations did not slifer from those in saline control animals (mean NI Nt samples in morphine-pres. treated rats is. saline controls. $f(11)=11.23, P:=(1,22)$, and were higher than during spontaneous withdrawal (ats'lage of $\mathrm{N} / \mathrm{N}+$ silm

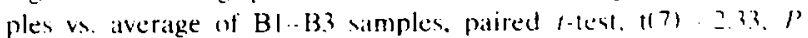
$0 .(15.3)$. 


\section{Results}

\subsection{Experiment 1: Withdrawal from morphine}

\section{Histology}

Fig. 1 (left) illustrates the location of the dialysis probes in the ventral-medial striatum of animals used in this experiment.

\section{Dialysis}

Fig. 2 shows the mean ( \pm S.E.M.) concentration of DA in dialysate for each group during the entire dialysis test session. Fig. 2 shows that there was a significant decrease in the basal concentration of DA obtained from animals undergoing spontaneous withdrawal from morphine (intervals B1-B3). Indeed, the basal concentration of DA in morphine-dependent animals $(0.43 \pm$ $0.05 \mathrm{pg} / \mu 1$ ) was approximately half that in saline-pretreated animals $(0.81 \pm 0.10 \mathrm{pg} / \mu \mathrm{l}$; see the figure legends for presentation of statistical analyses).

In saline-pretreated animals, morphine administration produced a significant increase in DA concentrations (intervals $\mathrm{M} 1-\mathrm{M} 3$ ), which was reversed transiently by subsequent naloxone administration (intervals $\mathrm{N} 1-\mathrm{N} 2$ ). Naloxone alone had no effect in control animals (Fig. 2). In morphine-dependent animals the administration of morphine also produced a significant increase in DA concentrations (see Fig. 2), which was reversed by a naloxone challenge (intervals $\mathrm{N} 1-\mathrm{N} 4$ ). It is important to note, however, that following the naloxone challenge DA concentrations in morphine-dependent animals did not return to the depressed levels seen during spontaneous withdrawal, and in fact, during intervals $\mathrm{N} 1-\mathrm{N} 4$ DA concentrations in morphine-dependent animals did not differ significantly from those in saline control animals.

\section{Behacior}

Fig. 3 shows the average behavioral withdrawal ratings over the entire dialysis test session. Also, the average concentration of DA in dialysate is replotted from Fig. 1 for morphine-dependent animals given naloxone, and for saline control animals, to facilitate comparison of the behavioral and neurochemical data.

As expected, morphine-dependent animals exhibited spontaneous symptoms of withdrawal 1 day after their last pretreatment injection of morphine (intervals B1B3; Fig. 3). Morphine administration eliminated the symptoms of withdrawal in morphine-dependent animals (i.e., there were no group differences in withdrawal ratings during intervals $\mathrm{M} 1-\mathrm{M} 3$ ). Naloxone administration reinstated withdrawal symptoms in morphine-dependent animals, but had no effect on saline control animals (intervals N1-N2). Naloxone-precipitated withdrawal was maximal for about $1 \mathrm{~h}$ after naloxone administration, but by the second hour (inter- vals N3-N4) withdrawal symptoms had dissipated. By the second hour after naloxone administration morphine-dependent animals did not differ from control, and also showed significantly fewer symptoms of withdrawal than at the beginning of the test session (i.e., intervals B1-B3 vs. N3-N4). Morphine-dependent animals given morphine followed by saline (instead of naloxone) did not show symptoms of withdrawal during intervals N1-N4 (data not shown).

A direct comparison of withdrawal symptoms and extracellular DA over the entire test session is especially interesting (Fig. 3). Spontancous withdrawal was associated with a decrease in the concentration of DA in dialysate, and the alleviation of withdrawal symptoms by morphine replacement was associated with an increase in DA concentrations. Reinstatement of withdrawal symptoms by naloxone was accompanied by a decrease in DA concentrations. These results suggest a correlation between the concentration of DA in dialysate and the presence or absence of withdrawal symptoms. Fig. 3 also shows, however, clear dissocia-

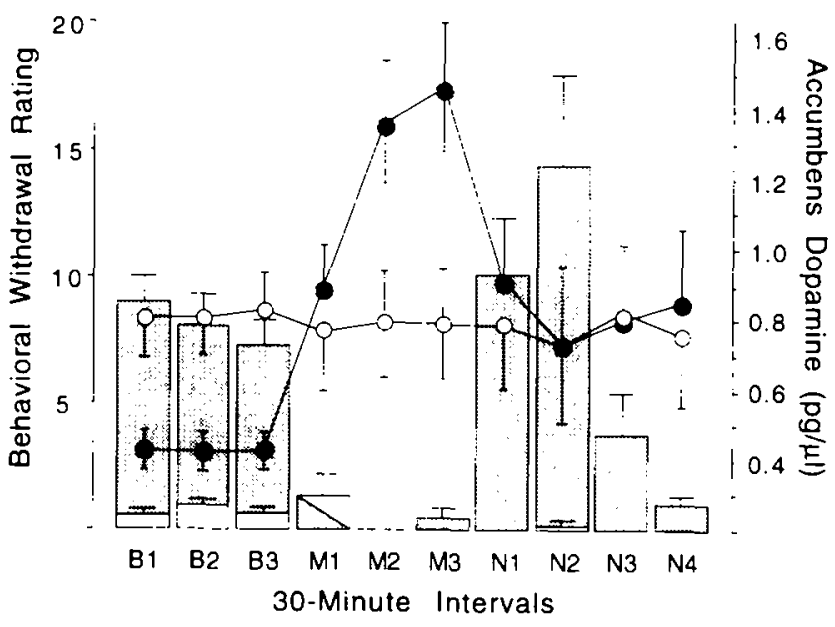

Fig. 3. Each bar represents the mean ( \pm S.E.M.) rating of morphine withdrawal symptoms cumulated over 30 -min intervals. The shaded bars represent ratings for morphine-pretreated (dependent) rats, and the open bars represent ratings for saline-pretreated rats. The closed circles represent the mean ( \pm S.E.M.) DA concentrations in dialysate for morphine-dependent rats given morphine followed by naloxone, and the open circles DA concentrations for the saline control group. The neurochemical data are replotted from Fig. 2 to facilitate comparison of the behavioral and neurochemical data. Summary of the statistical analyses. (1) Morphine-dependent animals showed spontaneous symptoms of withdrawal (mean ratings over intervals B1-B3 for saline-pretreated vs. morphine-pretreated rats, MannWhitney $U$ test. $U=0.0, P<0.0001$ ). (2) Morphine administration significantly reduced withdrawal symptoms in morphine-dependent rats (mean ratings for intervals $\mathrm{B} 1-\mathrm{B} 3$ vs. $\mathrm{M} 1-\mathrm{M} 3$, paired sign test, $P<0.0001$ ), and for intervals M1-M3 morphine-dependent rats did not differ from control (Mann-Whitney $U$ test). (3) Naloxone increased withdrawal symptoms in morphine-dependent rats for approximately $1 \mathrm{~h}$ (ratings for intervals $\mathrm{M} 1-\mathrm{M} 3 \mathrm{vs}$. N1-N2, paired sign test, $P=0.002$ ), but by the second hour after naloxone administration symptoms of withdrawal dissipated (ratings for intervals M1-M3 vs. N3-N4, paired sign test, $P=0.34)$. 
Iatilc I

The mean - S.I. M. concentrations of dopamine. dihydroxyphenyt. acetic acid (DOPAC), homosanillic acid (IIVA) and 5-hydroxyin

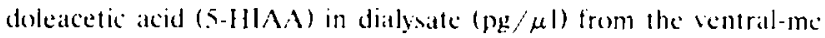
dial striatum of rats pretreated with saline or amphetamine (AMPI) and withdrawn for $2+$ h: half the animals were given anesthesial immediately prior to prote implantation. the dity before dialssis testing

\begin{tabular}{|c|c|c|c|c|}
\hline (iroup) & Iopamine & IOOPAC & HIV & $5-H A N$ \\
\hline $\begin{array}{l}\text { Saline-pretleated } \\
\text { no ancsthesia }(n-5)\end{array}$ & $0.671+0.11$ & $573 \cdot 75$ & $310+42$ & $205+18$ \\
\hline $\begin{array}{l}\text { Saline-pretrealed } \\
\text { anesthesia }(n=x)\end{array}$ & $10.86 .3+11.1 .5$ & $621+5.3$ & $.371: .3 x$ & $214+18$ \\
\hline $\begin{array}{l}\text { AMPI-pretreated. } \\
\text { no anesthesiat }(n=5)\end{array}$ & $11.760+11.11$ & $716 \pm 55$ & $362+33$ & $20.5 \pm 1.5$ \\
\hline $\begin{array}{l}\text { AMPli-preirealled. } \\
\text { anesthesia }(n=\delta)\end{array}$ & $0.0 .37 \pm 0.017$ & $517+45$ & $2 \times 5 \pm 22$ & $220+17$ \\
\hline
\end{tabular}

tions between the concentration of DA in dialysate and the severity of withdrawal symptoms. First, although naloxone administration precipitated severe withdrawal symptoms (intervals $\mathrm{N} 1-\mathrm{N} 2$ ). extracellular DA only decreased to levels seen in saline-pretreated rats. That is, during the first hour after naloxone administration. when withdrawal symptoms were the most pronounced. the concentration of DA in dialysate obtained from morphine-dependent animals did not differ from control, and was significantly higher than during spontaneous withdrawal (intervals BI-B3). Second. in morphine-dependent animals the concentration of DA in dialysate was constant over the $2 \mathrm{~h}$ following naloxone administration, but over this same period of time the symptoms of withdrawal ranged from their maximum (intervals $\mathrm{N} 1-\mathrm{N} 2$ ) to near minimum (interval N4).

\subsection{Experiment 2: Withdrawal from amphetamine}

Fig. I (right) illustrates the location of the dialysis probes in the ventral-medial striatum of animals used in this experiment. The mean basal concentrations of DA, DOPAC, HVA and 5-HIAA in dialysate for each group are given in Table 1. There was no effect of amphetamine withdrawal, or treatment with anesthesia $24 \mathrm{~h}$ previously, on the concentrations of any of these compounds in dialysate, as determined by one-way analyses of variance: DA, $F(3,30)=0.799, P=0.5(14$ DOPAC, $F(3,30)=2.164, P=0.11 .3$; HVA. $F(3,30)=$ 1.440. $P=0.251$; 5-HIAA, $F(3,30)=0.199 . P=0.896$.

\section{Discussion}

Symptoms of spontancous morphine withdrawal were clearly evident $\mathrm{I}$ day following discontinuation of chronic morphine treatment. Consistent with previous reports $[1.2,16]$ (c.f. [1.3]). spontancous morphine with- drawal was associated with a significant decrease in the extracellular concentration of DA in the ventral stris. tum, als estimated by in vivo microdialysis. Morphine replacement alleviated withdrawal symptoms, and increased the extracellular concentration of DA. These data are consistent with the hypothesis that a depres. sion in extracellular DA may contribute to some of the symptoms of morphine withdrawal [2.16.18|.

On the other hand, the experiment involving natoxone-precipitated withdrawal shows that the symptoms of morphine withdrawal can be dissociated from the extracellular concentration of DA. at least in the ventral-medial striatum. suggesting that the correlation described above may not be indicative of a direet causal relationship. Two examples of a dissociation between morphine withdrawal symptoms and extracellular DA were found. First. although naloxone administration precipitated severe withdratwal symptoms. the dose of naloxone used here only decreased DA concentrations to control levels: not to the depressed levels seen during spontaneous withdratual. Second. the time course of naloxone-precipitated withdrawal symptoms was not correlated with change's in the concentration of DA in dialysate. Following naloxone administration. the withdrawal symptoms seen in morphine-dependent rats ranged from their maximum during the first hour. to near minimum during the last 30 min of the test session. Despite this marked variation in withdrawal symptoms. there was no change in extracellular DA over the same period of time. These dissociations between withdrawal symptoms and the concentration of DA in dialysate suggest that the symptoms of morphine withdrawal cannot be caused solely by variattion in the extracellular concentration of DA in the ventral-medial striatum.

This conclusion requires a couple of caveats. First. although our data suggest that the symptoms of norphine withdrawal cannot be attributed rolely to abnormally low extracellular concentrations of DA in the ventral-medial striatum. this does not mean that changes in striatal DA neurotransmission play no rolo in morphine withdrawal. The data only establish that variation in the symptoms associated with morphino withdrawal cannot be explained by variation in the extracellular concentration of DA alone. There may be a variety of complex presynaptic and postsynaptic adaptations in DA systems that occur during chronic exposure to morphine, and interactions between vartous neuroadaptations in DA systems may contribute 11 the morphine withdrawal syndrome. The nature of such putative interactions, and their relationship to the morphine withdrawal syndrome. remain to be determined. Second, the most obvious physical signs of withdrawal were quantified in the present study. not the aversive subjective experiences that some re searchers have proposed maly be mediated by changes 
in DA neurotransmission $[2,16,18]$. It is always possible, therefore, that there was no dissociation between the subjectice symptoms of withdrawal and extracellular DA concentrations. This would require, however, that in this experiment subjective symptoms were absent when the physical signs of withdrawal were maximal.

In contrast to the decrease in extracellular DA associated with spontaneous morphine withdrawal, there was no change in extracellular DA in the ventral-medial striatum during amphetamine withdrawal. This is consistent with a number of reports of no change in the basal extracellular concentration of DA in the nucleus accumbens over the first 5 days of amphetamine withdrawal $[4,19,22]$; but seems inconsistent with Rossetti et al. [16], who reported a significant decrease in extracellular DA in the ventral striatum for 5 days following the discontinuation of chronic amphetamine treatment.

It is not clear what accounts for the discrepancy between the present study (and also [4,19,22]), and that of Rossetti et al. [16]. Our previous study of amphetamine withdrawal [4], in which a quantitative ('no net flux') microdialysis method was used, differed from that of Rossetti et al. [16] in at least three potentially significant ways. First, in our previous study an escalating dose amphetamine pretreatment regimen was used, in which each of six weekly cycles of five successive drug days were followed by two drug-free days. Thus, in this experiment animals expcrienced withdrawal sevcral times prior to the dialysis test session ([22] as well), whereas, in the Rossetti et al. experiment [16] animals experienced withdrawal for the first time during the dialysis test session. This raises the possibility that the response to the first experience of amphetamine withdrawal may differ from subsequent experiences. In the present experiment, therefore, we used exactly the same pretreatment regimen as Rossetti et al. [16], thus eliminating this variable. Second, Rossetti et al. [16] reported the amphetamine withdrawal-associated decrease in DA was maximal the first day following the discontinuation of amphetamine pretreatment, but in the other studies cited above animals were tested between three and five days of withdrawal. Although symptoms of amphetamine withdrawal persist for up to 7 days following the discontinuation of escalating dose amphetamine treatment $[9,11]$, animals in the present study were examined on the first day of withdrawal to maximize the probability of detecting a withdrawal-related decrease in DA concentrations. Third, in the Rossetti et al. [16] experiment animals received anesthesia the day prior to the dialysis experiment, and in the other studies they did not. This raises the possibility that the decrease in extracellular DA reported by Rossetti et al. [16] was due to an interaction between residual effects of anesthesia and amphetamine with- drawal. To test this possibility in the present study, half the animals received anesthesia the day prior to the dialysis test session and half did not. Prior anesthesia had no effect on extracellular DA in the ventral-medial striatum. In conclusion, these three variables do not seem to account for the decrease in extracellular DA reported by Rossetti et al. [16].

Two other possibilities deserve mention. One, different style microdialysis probes were used in different studies. Rossetti et al. [16] used transverse probes, and concentric vertical probes were used in the present experiment, and by others $[4,19,22]$. The implantation of a transverse probe requires a major surgical procedure the day before the dialysis test session. It is possible, therefore, that the decrease in DA observed by Rossetti et al. [16] was not due to amphetamine withdrawal alone, but to an interaction between the discomfort associated with recent surgical trauma and that associated with amphetamine withdrawal. A second possibility is that transverse probes sample a different portion of the ventral striatum than the concentric probes used here and by others $[4,19,22]$, and the effect of amphetamine withdrawal on extracellular DA is regionally specific. Consistent with this hypothesis, we found recently that withdrawal from escalating dose amphetamine treatment is associated with a transient decrease in extracellular DA in the dorsolateral caudate nucleus, but not the nucleus accumbens (P. Paulson and T. Robinson, unpublished observations), suggesting there are indeed regional differences in the effects of amphetamine withdrawal on DA neurotransmission.

In summary, under some experimental conditions there may be an association between the extracellular concentration of DA in the ventral striatum and amphetamine or morphine withdrawal, but the data presented here suggest this correlation probably is not due to a necessary, causal relationship. First, during morphine withdrawal it was possible to dissociate variation in the symptoms of withdrawal from variation in extracellular DA concentrations. Second, amphetamine withdrawal was not associated with any change in the concentration of extracellular DA in the ventral-medial striatum. Although the present study does not rule out the possibility that other, more complex, changes in DA ncurotransmission play a role in drug withdrawal syndromes, it does suggest that a simple decrease in extracellular DA in the ventral-medial striatum is not a common feature of drug withdrawal syndromes, and does not play a simple causal role in producing the symptoms of opiate withdrawal.

\section{Acknowledgements}

This research was supported by a grant from the National Institute on Drug Abuse (04294). We thank 
Dianne Camp and Keith Trujillo for their helpful comments and advice, and Kaitlen Browman. Hans Crombag. Steve Simmerville and Sonal Solanki for their assistance in conducting the experiments.

\section{References}

(1) Acquas. E... Carboni. F. and Di Chiara. G.. Profound depression of mesolimbic dopamine release after morphine withdrawal in dependent rats. Eur. J. Pharmacol. 193 (1991) 13313.

[2] Acquas. F. and Di (hiara. (i.. Depression of mesolimbic dopamine transmission and sensitization to norphine during upiate abstinence. J. Veurochem., 58 (1992) 16201-1625.

[3] Blasig. J.. Her\%. A.. Reinhold. K. and Zieglgansberger. S. Development of physical dependence on morphine in respect to time and dosage and quantification of the precipitated withdrawal syndrome in rats. Psychopharmescologia, 3.3 (147.3) 19.38.

[4] Crippens. D. Camp. D.M. and Robinson. T.E.. Basal extracellulat dopamine in the nucless accumbens during amphetamine withdrawal: a 'no net thux' microdialysis study. Neuroset. left. $164(1993) 145 \cdot 148$

(5) Dianla. M. Pistis, M. Carboni. S. Ciessa, (i.l.. and Rossetti. 7...... Profound decrement of mesolimbic dopaminergic neuronal activity during ethanol withdrawal syndrome in rats: electrophysiological and hiochemical evidence. Pros. Nutl acud. Sict. (:S.4.90(1093) 7966,7969

[6] Imperalto, A. Mele. A. Scrocos, M.Ci. and Puglisi-Allegra, S. (hronic cocaine alters limbic extracellular dopamine. Neurochemical hasis for addiction. Eur. J. Pharmacol. 212 (1992) $2093(01)$.

[7] Jaffe. J.H.. Drug addiction and Jrug abuse. In A.C. Gilman. I.W. Rall. A.S. Nies and P. Taylor (Eds.). The Pharmacological Bass of Therapeates, Pegamon Press. New York. 19911. pp 522573.

[i] Moghadddam. B. and Bunney. B.S. Ionic composition of microdialysis perfusing solution alters the pharmacological responsiveness and basal outflow of striatal dopamine. J. Neurochem. $53(1989) 6,526.54$.

[9] Munn. L.M. and Wise. R.A. The effect of escalating dose's of (-amphetamine (AMPH) on lateral hypothalamic intracranial self-stimulation (ICSS). Soc. Neurosci. Ahstr. 18 (1902) 364.

[10] Paroms. L..H.. Smith. A.D. and Justice. J.B.. Jr.. Basal extracelJular dopamine is decreased in the rat nucleus accumbens during abstinence from chronic cocaine. Sinapse. 9(1991) 601-65.

[II] Paulon. P.E... Camp. D.M. and Robinson. T.E... The time

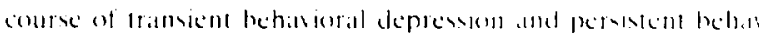

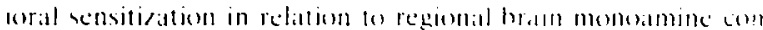

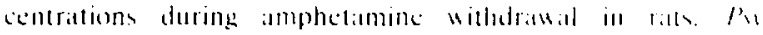

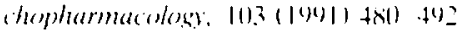

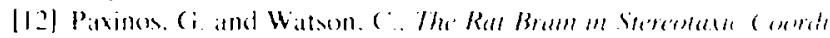
nater. Raven Press, ven rark. lusen

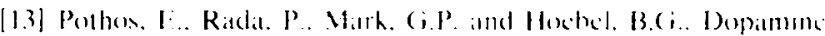

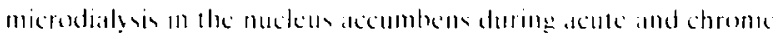
morphine, naloxome-precipitated withotranal and clomidine

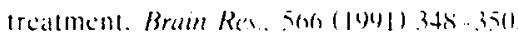

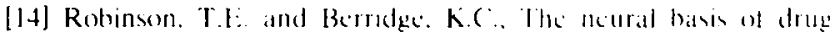
craving: an incentive-semsitisation theors al addiction. Bram

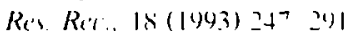

[15] Robinson, T.t: and ( amp. D.M., The teashility of repeatled microdialysis for withan-subjects design experinents: stadien on the mesostriatal dopamine system. In T.I. Robinson and I.B

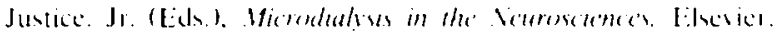
Amsterdam. 1991. Dp. 146 234

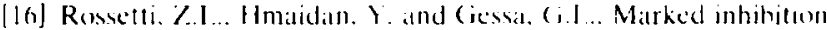
of mesolimbic dopamine release: a conmon leature bl sthands. morphinc. cocalne and amphetamine ahstinence in rals, Fat I Phamacol. 221 (19) 201 20? 23.4

[17] Rosedti. K.I... Melis, V.. (atbont. S. D)ianal. M. and (iemal (i.I . Alcohol withdrawal in rats is associated with a matrked tall

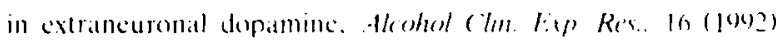
$520-532$

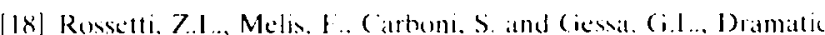
depletion of mesolimbic extracellular dopaning aller with drawal from morphince alcohol of cocalle: a common neturo. chemical substrate for drug dependence. In P.W. Kalisats and

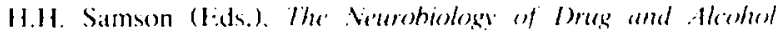

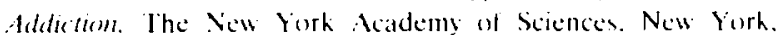
1902. Dp. 51.3516.

[19] Segal], [).S. and Kuczenski. R. In vivo microdialysis reveals it diminished amphetannine-induced I) A response corresponding lo behavioral sensitization produced by repeated ampletaminc pretreatlment. Brain Res. 571 (1992) 3.30 .337

[2(0] Weiss. F. Markou. A. Iorang. M.T. and kooh. (i.J., Batsal extracellulat dopamine levels in the nucleus accumbens ale decreased during cocanc withdrawal aflet unlimited-acoses self-administration. Brain Res. 593 (1992) 31.4 31.

[21] Wisc. R.A. and Bozarth. M.A. A psychomotor stimulant theory

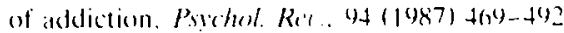

[22] Wolf. M.F... White, P.I. Vassar. R. Bromdersun. R.I. and Khansa. M.R.. Difterential development of atutoreceptor subsomstivity and enhanced dopamine release during amphestamino

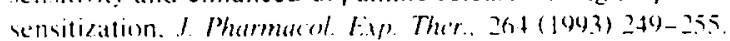

